\title{
Both Pulmonary and Extra-Pulmonary Factors Predict the Development of Disability in Chronic Obstructive Pulmonary Disease
}

\author{
Jonathan P. Singer ${ }^{a, b}$ Patricia P. Katz ${ }^{d} \quad$ Carlos Iribarren $^{f} \quad$ Theodore A. Omachi $^{a, b}$ \\ Gabriela Sanchez ${ }^{f}$ Edward H. Yelin ${ }^{d}$ Miriam G. Cisternas ${ }^{e}$ Paul D. Blanc $^{\mathrm{a}-\mathrm{c}}$ \\ ${ }^{\mathrm{a}}$ Division of Pulmonary, Critical Care, Allergy and Sleep Medicine, Department of Medicine, and ${ }^{\mathrm{b}}$ Cardiovascular \\ Research Institute and ' Division of Occupational and Environmental Medicine, Department of Medicine and \\ ${ }^{d}$ Institute for Health Policy Studies and Department of Medicine, University of California, San Francisco, Calif., \\ eMGC Data Services, Carlsbad, Calif., and f Kaiser Permanente Division of Research, Oakland, Calif., USA
}

\section{Key Words}

Chronic obstructive pulmonary disease $\cdot$ Disability

Exercise capacity · Functional limitation

\begin{abstract}
Background: Although chronic obstructive pulmonary disease (COPD) is a major cause of disability worldwide, its determinants remain poorly defined. Objective: We hypothesized that both pulmonary and extra-pulmonary factors would predict prospective disablement across a hierarchy of activities in persons with COPD. Methods: Six hundred and nine participants were studied at baseline $\left(T_{0}\right)$ and 2.5 years later $\left(\mathrm{T}_{1}\right)$. The Valued Life Activities (VLA) scale quantified disability (10-point scale: $0=$ no difficulty and $10=$ unable to perform), defining disability as any activity newly rated 'unable to perform' at $\mathrm{T}_{1}$. Predictors included pulmonary (lung function, 6-minute walk distance and COPD severity score) and extra-pulmonary (quadriceps strength and lower extremity function) factors. Prospective disability risk was tested by separate logistic regression models for each predictor (baseline value and its change, $\mathrm{T}_{0}-\mathrm{T}_{1}$; odds ratios were scaled at 1 standard deviation per factor. Incident disability across a hierarchy of obligatory, committed and discretionary VLA subscales was compared. Results: Subjects manifested a
\end{abstract}

$40 \%$ or greater increased odds of developing disability for each predictor (baseline and change over time). Disability in discretionary activities developed at a rate 2.2-times higher than observed in committed activities, which was in turn 2.5-times higher than the rate observed in obligatory activities ( $p<0.05$ for each level). Conclusions: Disability is common in COPD. Both pulmonary and extra-pulmonary factors are important in predicting its development.

Copyright $\odot 2012$ S. Karger AG, Base

\section{Introduction}

Disability among working-aged adults is a critical, yet understudied health outcome that has been identified as a priority for further research [1]. Chronic obstructive pulmonary disease (COPD) currently ranks within the top 5 causes of disability among working-aged adults in the USA and, by 2020, is projected to rank 5th wordwide $[2,3]$. Indeed, people with COPD have a 10 -fold greater risk of disability than the general population [4]. Despite its importance, however, the pathways leading to COPDrelated disability remain poorly characterized.

COPD is particularly relevant to the disablement process because it manifests as a systemic disease with both

\section{KARGER}

E-Mail karger@karger.com

www.karger.com/res (c) 2012 S. Karger AG, Basel

0025-7931/13/0855-0375\$38.00/0
Jonathan Singer, MD, MS

University of California, San Francisco

505 Parnassus Avenue, M1097

San Francisco, CA 94143-0111 (USA)

Tel. +1 415476 6030, E-Mail jon.singer@ucsf.edu 
pulmonary and extra-pulmonary features [5]. These manifestations include elevations in biomarkers [6] and gene expression [7] related to systemic inflammation, poor muscle function [8] and frailty [9]. Moreover, people with COPD experience a myriad of comorbidities, including atherosclerosis [10], depression [11], osteoporosis [12] and chronic disease anemia [13]. To date, disability in COPD has been predominantly studied from the narrow perspective of activities necessary for survival or basic functioning such as (instrumental) activities of daily living [(I)ADLs] [14-18]. The inability to perform such activities, however, typically develops late, in relatively advanced disease. Not only does this narrow construct of disability underestimate the burden of COPD-related morbidity, but it also provides little insight into the earlier stages of disablement that might be more amenable to intervention.

Nagi [19] advanced disability research by proposing a conceptual model of disablement that was modified by Verbrugge and Jette [20] and that has since been widely adopted. This model proposes that disability begins with alterations in the functioning of a body organ affected by disease, resulting in impairment. Impairment brings about reductions in physical or mental actions conceptualized as functional limitations. Functional limitations, in turn, lead to disability across a hierarchy of activity levels. Findings from our previous work analyzing disablement in COPD are consistent with this model [21].

We conducted a prospective longitudinal study of working-aged adults with COPD to characterize the development of disability. We aimed to determine whether changes over time in pulmonary and extra-pulmonary impairment and functional limitations predicted the prospective development of disability. We further aimed to distinguish the development of such disability across a hierarchy of activity domains: obligatory activities that are required for survival and independence - e.g. (I) ADLs, committed activities that define one's principal social roles - e.g. working for pay or caring for family) and discretionary activities - e.g. involvement in hobbies, socializing or travel).

\section{Methods}

Subjects and Design

We used data from the Function, Living, Outcomes and Work (FLOW) study, an ongoing prospective longitudinal cohort study of working-aged adults (age: 40-65 years at baseline) recruited from an integrated health care delivery system. The FLOW cohort consists of 1,202 Kaiser Permanente Medical Care Program
(KPMCP) members with COPD recruited using a validated algorithm based both on recent health care utilization linked to a COPD diagnostic code and pharmacy dispensing for COPD-related medications; recruitment methods have been described previously [22]. At baseline study Wave $1\left(\mathrm{~T}_{0}\right)$, we conducted structured telephone interviews that ascertained sociodemographic characteristics, COPD clinical history and health status. We also conducted a clinic visit to perform spirometry and other physical assessments. Approximately 2.5 years later $\left(\mathrm{T}_{1}\right)$, we successfully conducted Wave 2 follow-up interviews on 1,051 (90\%) of those subjects studied at baseline (fig. 1). After exclusions for ineligibility for or inability to follow-up with clinic visits, we performed repeat clinic visits on 677 (69\%) of 987 participants. For this study, we excluded 68 subjects (10\%) because of unacceptable spirometric data at either $\mathrm{T}_{0}$ or $\mathrm{T}_{1}$.

At the time of baseline assessments, we recruited 302 age- and gender-matched referents who were KPMCP members without a COPD diagnosis or obstruction on spirometry. We used these referent data to derive normative values for quadriceps strength [9], but did not otherwise include them in the analyses we present here.

Protocols were approved by the UC San Francisco Committee on Human Research and the Kaiser Foundation Research Institutional Review Board.

\section{Independent Predictor Variables}

Respiratory Impairment

Pulmonary Function. We assessed respiratory function by spirometry according to American Thoracic Society (ATS) guidelines [23]. Spirometry was performed with the EasyOne ${ }^{\mathrm{TM}}$ Frontline spirometer (ndd Medical Technologies, Chelmsford, Mass., USA). We applied percent predicted $\mathrm{FEV}_{1}$ values from the regression equations developed from the National Health and Nutrition Examination Survey III [24].

COPD Severity Score. This is a novel, validated survey-based disease severity instrument that does not require physiologic measures of respiratory function or exercise capacity [25]. This feature makes it useful for epidemiologic studies and telephone administration. The COPD severity score is based on items spanning five domains: (1) severity of respiratory symptoms, (2) prior use of systemic corticosteroids, (3) use of other COPD medications, (4) previous hospitalization or intubation for respiratory causes and (5) use of long-term oxygen therapy. It ranges from 0-35; higher scores reflect greater disease severity and correlate with $\mathrm{FEV}_{1}, \mathrm{BODE}$ Index, exercise capacity and health-related quality of life [26, 27].

\section{Nonrespiratory Impairment}

Exercise Capacity. Exercise capacity was measured using the 6-minute walk test (6MWT) [28]. We used a standardized flat, straight course of $30 \mathrm{~m}$ in accordance with American Thoracic Society guidelines. Every $2 \mathrm{~min}$, a technician used standardized phrases to encourage effort.

Quadriceps Strength. Decreased quadriceps strength is associated with poorer exercise capacity and lower extremity functioning across a spectrum of COPD severity $[9,29]$. Isometric quadriceps strength was assessed by standard manual muscle testing procedures using a hand-held dynamometer (MicroFet2 dynamometer, Saemmons Preston, Bolingbrook, Ill., USA) [30]. Examiners trained in manual muscle testing by the same experienced 


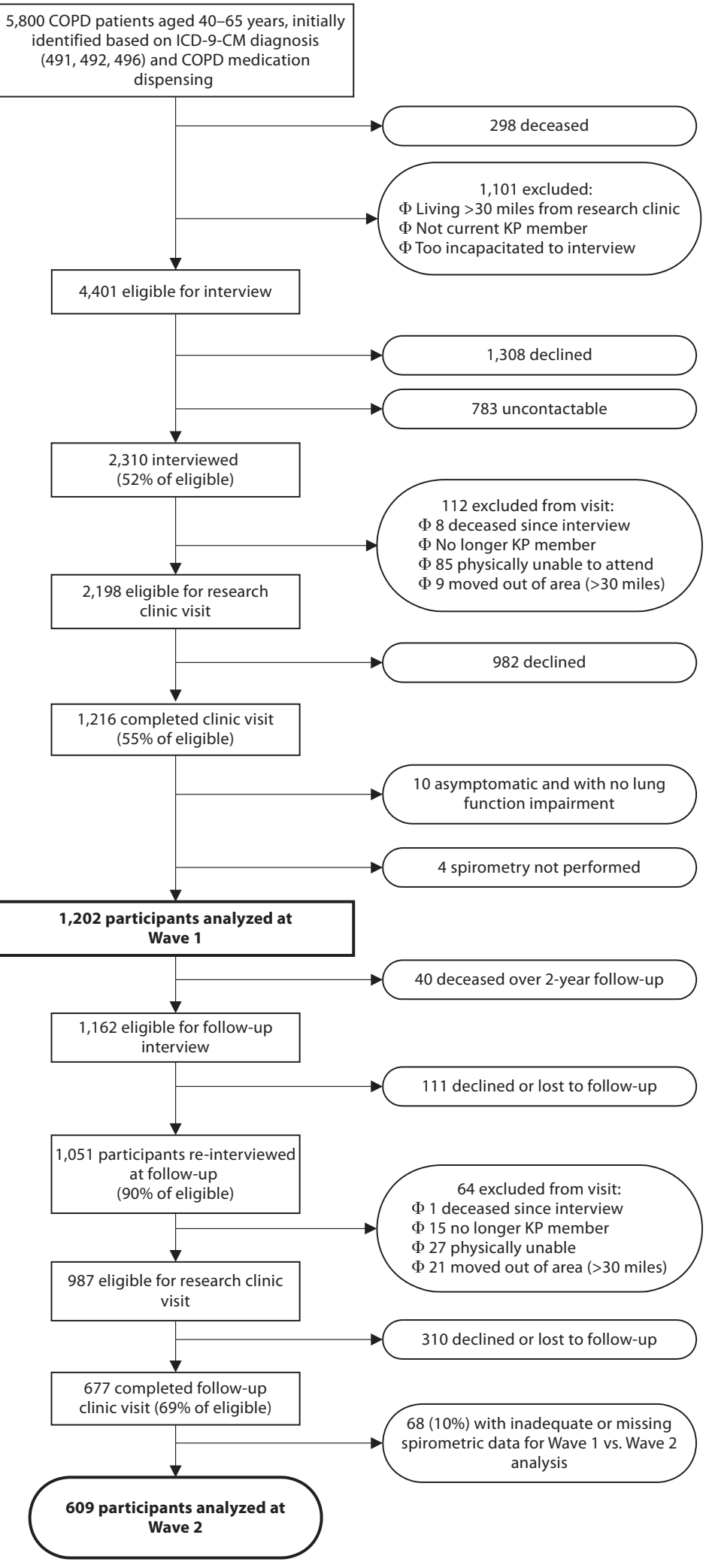

Fig. 1. FLOW study recruitment and retention. 
physical therapist practised testing until there was agreement between the raters $90 \%$ of the time within $2.3 \mathrm{~kg}$ of force. We focused on quadriceps strength because these muscles are considered essential for walking and previous studies have suggested the importance of quadriceps weakness as a predictor of reduced exercise capacity in COPD [31].

Lower Extremity Functioning. This was quantified using the validated Short Physical Performance Battery (SPPB) [32]. Poorer SPPB performance is predictive of incident disability, institutionalization and mortality in older people, independent of comorbidity or socioeconomic factors [32,33]. This battery includes 3 performance measures of balance, chair stands and a 4-meter walk, each scored from 0 to 4 points. A summary score ranges from 0 to 12 .

\section{Outcome Variables}

Disability was measured by the Valued Life Activities disability scale (VLA) [34]. The VLA scale makes operational the broad conceptual hierarchy of disability proposed by Verbrugge and Jette [20]. Originally developed for rheumatoid arthritis, the VLA scale measures complex functioning in daily life and has subsequently been validated in asthma and COPD [35]. Originally comprising 32 items, refinements over the past decade have resulted in shorter scales. For this study, a 22 -item scale was employed; respondents rated on a 10-point scale how difficult, due to their breathing problems, activity performance was across 22 obligatory, committed and discretionary domains $(0=$ no difficulty and $10=$ unable to perform the activity). The VLA scale was administered at $\mathrm{T}_{0}$ and $\mathrm{T}_{1}$ and change scores were derived. Incident disability was defined in two ways: (1) a new rating of 'unable' in any activity domain from $\mathrm{T}_{0}$ to $\mathrm{T}_{1}$ or (2) a $1 / 2$ standard deviation increase in the mean difficulty rating across all rated items, which we defined as a 'meaningful change' in mean disability, consistent with prior definitions [35]. We evaluated the overall scale in this manner as well as within the hierarchy of obligatory, committed and discretionary subscales.

\section{Other Covariates}

We included variables that might confound the relationships between the predictor and outcomes measures of interest. These included sociodemographic characteristics (age, sex and race) as well as cigarette-smoking history using questions refined from the National Health Interview Survey and second-hand smoke exposure using items we had originally developed [36, 37].

\section{Statistical Analysis}

Categorical variables were analyzed with the $\chi^{2}$ test. Continuous variables were analyzed with the Student $t$ test (by follow-up status) or the paired $t$ test (for change $\mathrm{T}_{0}-\mathrm{T}_{1}$ ). We examined the impact of baseline $\left(\mathrm{T}_{0}\right)$ and change $\left(\mathrm{T}_{0}-\mathrm{T}_{1}\right)$ in 5 respiratory and nonrespiratory predictors on the prospective risk of VLA disability. Predictors, including $\mathrm{FEV}_{1}, 6 \mathrm{MWT}$, COPD severity score, quadriceps strength and SPPB were tested in separate multivariable logistic regression models that included the baseline value of the predictor as well as its change over time. We tested the impact of each predictor on the two definitions of VLA disability. Odds ratios (ORs) were expressed per Z unit [1 standard deviation (SD)] change in each predictor. Each model was tested for two prospective VLA outcomes: incident disability and a meaningful (0.5 SD) increase in mean difficulty rating. All models included gender, age (continuous variable), race [categorized as white/non-Hispanic (referent), black or all others], BMI (continuous variable), change in BMI from $\mathrm{T}_{0}$ to $\mathrm{T}_{1}$, smoking (packs per day), and second-hand smoke exposure (hours per week). Since they were the most consistent predictors of VLA disability, we used multivariable logistic regression to test the impact of 6MWT and COPD severity score on the risk of disability in the obligatory (e.g. ADLs), committed (e.g. working for pay) and discretionary (e.g. socializing or travel) VLA subscales controlling for gender, age, BMI, race, smoking status and second-hand smoke exposure. Given the ubiquitous use of spirometric measures as a measure of COPD severity, we also tested the impact of percent predicted $\mathrm{FEV}_{1}$ on the VLA subscales, controlling for the same covariates used in the $6 \mathrm{MWT}$ and COPD severity score models. In sensitivity analyses, we defined BMI dichotomously as obese $(\mathrm{BMI}>30)$ versus not and change in BMI categorically as a $\geq 10 \%$ gain, $\geq 10 \%$ loss or other (referent). We also repeated analyses replacing the baseline value of each predictor with its average between $\mathrm{T}_{0}$ and $\mathrm{T}_{1}$.

Lastly, we hypothesized that discretionary activities would be more vulnerable to the development of incident disability than committed activities and, likewise, committed activities would be more vulnerable to disablement than obligatory activities. We compared the rates of disability in each activity domain as a ratio of a Poisson variable to its expected value based on the denominator rate [38].

Analysis was conducted using STATA/ICv11.2 (StataCorp, College Station, Tex., USA).

\section{Results}

Among 609 study participants analyzed (table 1), 367 $(60 \%)$ were female with a mean age of $59.3 \pm 6.1$ years, and mean baseline $\mathrm{FEV}_{1}$ was $1.79 \pm 0.74$ liters $(64 \% \pm$ 23 predicted). Most subjects (85\%) were either current or former smokers. The mean time between study visits was $2.4 \pm 0.5$ years. Compared to subjects included in the analysis, reinterviewed subjects without follow-up research clinical data $(n=310)$ were more likely $(\mathrm{p}<0.05)$ to be current smokers and have lower baseline $6 \mathrm{MWT}$ distances, but did not otherwise differ by any of the other variables shown in table 1 (data not shown).

Changes in the independent predictors from $\mathrm{T}_{0}$ to $\mathrm{T}_{1}$ are presented in table $2 . \mathrm{FEV}_{1}$ and percent predicted $\mathrm{FEV}_{1}$ declined by $0.10 \pm 0.25$ liters and $1.9 \pm 8.7 \%$, respectively (both $\mathrm{p}<0.0001$ ). These declines, however, were not consistently observed. Over the follow-up period, $40 \%$ of subjects manifested essentially stable lung function.

Strong, consistent associations were identified between each physical performance measure $\left(\mathrm{FEV}_{1}, 6 \mathrm{MWT}\right.$, quadriceps strength and SPPB) and the development of incident disability, defined as any VLA activity newly reported as 'unable to perform' (table 3). These predictive 
Table 1. Baseline subject characteristics of the FLOW cohort study $(\mathrm{n}=609)$

\begin{tabular}{|c|c|}
\hline Subject characteristics & $\begin{array}{l}\mathrm{n}(\%) \text { or } \\
\text { mean } \pm \mathrm{SD}\end{array}$ \\
\hline Age, years & $59.3 \pm 6.1$ \\
\hline Sex, female & $367(60)$ \\
\hline BMI & $31.8 \pm 8.3$ \\
\hline \multicolumn{2}{|l|}{ Race/ethnicity } \\
\hline White, non-Hispanic & $421(69)$ \\
\hline Black & $105(17)$ \\
\hline Other & $83(14)$ \\
\hline Cigarette smoking, packs/day & $0.85 \pm 0.35$ \\
\hline Second-hand smoke exposure, h/week & $1.10 \pm 5.02$ \\
\hline \multicolumn{2}{|l|}{ Pulmonary function } \\
\hline $\mathrm{FEV}_{1}$, liters & $1.79 \pm 0.74$ \\
\hline Percent predicted $\mathrm{FEV}_{1}{ }^{\mathrm{a}}$ & $64 \pm 23$ \\
\hline $\mathrm{FEV}_{1} / \mathrm{FVC}$ & $0.61 \pm 0.15$ \\
\hline $6 \mathrm{MWT}, \mathrm{m}$ & $412 \pm 117$ \\
\hline \multicolumn{2}{|l|}{ Skeletal muscle strength } \\
\hline Quadriceps, kg of force & $27.1 \pm 9.3$ \\
\hline Quadriceps \% predicted ${ }^{\mathrm{b}}$ & $84.4 \pm 25.6$ \\
\hline SPPB & $10.6 \pm 1.8$ \\
\hline COPD severity score & $10.1 \pm 6.0$ \\
\hline \multicolumn{2}{|c|}{$\begin{array}{l}{ }^{a} \text { Percent predicted } \mathrm{FEV}_{1} \text { values derived directly from the lin- } \\
\text { ear regression equations developed from the National Health and } \\
\text { Nutrition Examination Survey (NHANES III) [24]. } \\
\text { b Muscle strength \% predicted values generated from } 302 \text { age- } \\
\text { and sex-matched control subjects without COPD, employing lin- } \\
\text { ear regression controlling for age, gender, BMI and height [9]. } \\
\text { SPPB = Short Physical Performance Battery. }\end{array}$} \\
\hline
\end{tabular}

associations were observed for both baseline measures as well as their change over time. ORs for incident disability per SD decrement in each performance measure were $\geq 1.43$ (95\% CI: 1.00-3.75; p values $<0.04$ ). Similarly, for each SD decrement in baseline COPD severity score as well as in changes over time, subjects had a 2.19 (95\% CI: $1.65-2.89)$ and 1.94 (95\% CI: 1.45-2.58) increased odds of developing incident disability, respectively ( $\mathrm{p}$ values $<0.01$ ).

For VLA disability, defined alternatively as a meaningful increase (1/2 SD) in the mean difficulty rating across activities, predictive associations of the 6MWT and COPD severity score with VLA disability remained strong, but were less consistent for $\mathrm{FEV}_{1}$ and SPPB (table 3). Moreover, quadriceps strength did not predict new disability by this definition. Overall, point estimates for the ORs for incident disability were lower when disability was defined as a meaningful increase in mean difficulty compared to previous analyses based on the new rating of 'unable' in any activity domain.

The Development of Disability in COPD
Table 2. Changes in characteristics of subjects from baseline to follow-up $(n=609)$

\begin{tabular}{lcc}
\hline Subject characteristics & Mean $\pm \mathrm{SD}$ & p value \\
\hline FEV $_{1}$, liters & $-0.10 \pm 0.25$ & $<0.0001$ \\
${\text { Percent predicted } \mathrm{FEV}_{1}{ }^{\mathrm{a}}}_{\text {}^{2}}$ & $-1.9 \pm 8.7$ & $<0.0001$ \\
Quadriceps, kg of force $^{\mathrm{b}}$ & $-36.1 \pm 84.1$ & $<0.0001$ \\
Quadriceps \% predicted & $0.8 \pm 7.5$ & 0.01 \\
SPPB & $1.8 \pm 23.0$ & 0.01 \\
COPD severity score & $0.1 \pm 1.5$ & 0.02 \\
BMI & $0.1 \pm 4.7$ & 0.70 \\
\hline
\end{tabular}

a Percent predicted $\mathrm{FEV}_{1}$ values derived directly from the linear regression equations developed from the National Health and Nutrition Examination Survey (NHANES III) [24].

${ }^{\mathrm{b}}$ Muscle strength \% predicted values generated from 302 ageand sex-matched control subjects without COPD, employing linear regression controlling for age, gender, BMI and height [9].

$\mathrm{SPPB}=$ Short Physical Performance Battery.

We next examined the impact of the COPD severity score and 6MWT, the two most consistent predictors of overall VLA disability, and percent predicted $\mathrm{FEV}_{1}$ on the development of disability in the obligatory, committed and discretionary VLA subscales (table 4). Both baseline COPD severity score and change in the COPD severity score over time were consistently predictive of incident disability across all subscales: the ORs for incident disability across scales per SD decrement in the COPD severity score were all $\geq 1.90$ ( $\mathrm{p}$ values $\leq 0.01$ ). Additionally, baseline $6 \mathrm{MWT}$ and percent predicted $\mathrm{FEV}_{1}$ predicted incident disability across all VLA subscales with estimated ORs of $\geq 2.6$ per SD decrement in $6 \mathrm{MWT}$ (p values $<0.01$ ). Change in 6MWT, however, predicted incident disability in only the discretionary subscale. Change in percent predicted $\mathrm{FEV}_{1}$ predicted incident disability in only the committed and discretionary subscales.

Eleven subjects (2\%) developed incident disability in the obligatory subscale, 27 (4\%) in the committed subscale and $60(10 \%)$ in the discretionary subscale. Disability in committed activities was 2.5 times more likely than obligatory activities disability, taking that as the expected rate (95\% CI: 1.27-4.54). In addition, disability in discretionary activities was 2.2 times more likely to develop than in committed activities (95\% CI: 1.5-3.2).

The results of the sensitivity analyses including alternative definitions of BMI and in other analyses replacing $\mathrm{T}_{0}$ predictor variables with the mean of $\mathrm{T}_{0}-\mathrm{T}_{1}$ were not substantively different from the results presented (data not shown). 
Table 3. Impact of change in characteristics on the development of incident disability in VLA

\begin{tabular}{|c|c|c|c|c|}
\hline Characteristic & \multicolumn{4}{|c|}{ Incident disability in VLA } \\
\hline Baseline $\mathrm{FEV}_{1}$ & $1.76(1.21-2.56)$ & $<0.01$ & $1.11(0.84-1.45)$ & 0.48 \\
\hline Decrement in $\mathrm{FEV}_{1}$ & $1.57(1.15-2.15)$ & $<0.01$ & $1.58(1.24-2.00)$ & $<0.01$ \\
\hline Decrement in $6 \mathrm{MWT}$ & $1.43(1.10-1.85)$ & $<0.01$ & $1.37(1.11-1.69)$ & $<0.01$ \\
\hline Baseline quadriceps strength & $1.75(1.18-2.58)$ & $<0.01$ & $1.08(0.80-1.46)$ & 0.63 \\
\hline Decrement in quadriceps strength & $1.39(1.00-1.95)$ & 0.05 & $1.09(0.85-1.42)$ & 0.49 \\
\hline Baseline SPPB & $1.85(1.42-2.41)$ & $<0.01$ & $1.32(1.05-1.66)$ & 0.02 \\
\hline Decrement in SPPB & $1.43(1.11-1.84)$ & $<0.01$ & $1.14(0.91-1.41)$ & 0.26 \\
\hline Baseline COPD severity score & $2.19(1.65-2.90)$ & $<0.01$ & $1.37(1.09-1.73)$ & $<0.01$ \\
\hline
\end{tabular}

${ }^{a}$ Newly unable to perform defined as a new rating of 'unable' in any activity domain from T0 to T1; a meaningful increase defined as a $1 / 2 \mathrm{SD}$ increase in the mean difficulty in rated items from T0 to T1.

${ }^{\mathrm{b}}$ ORs expressed per standardized $\mathrm{Z}$ unit (1 SD) decrements in $\mathrm{FEV}_{1}, 6 \mathrm{MWT}$, quadriceps strength or SPPB or increase in COPD severity score, all of which were tested in separate multivariable logistic regression models that included the baseline value of the predictor as well as its change over time. All models also include gender, age, BMI, change in BMI, race, smoking status and second-hand smoke exposure.

VLA $=$ Valued Life Activities.

Table 4. Impact of change in 6MWT and COPD severity score on the development of incident disability in subcategories of VLA

\begin{tabular}{|c|c|c|c|c|c|c|}
\hline \multirow[t]{3}{*}{ Characteristic } & \multicolumn{6}{|c|}{ Incident disability in newly unable to perform VLA by VLA subcategory ${ }^{a}$} \\
\hline & \multicolumn{2}{|c|}{ Obligatory $(n=11 / 609)(2 \%)$} & \multicolumn{2}{|c|}{ Committed $(\mathrm{n}=27 / 609)(4 \%)$} & \multicolumn{2}{|c|}{ Discretionary $(n=60 / 609)(10 \%)$} \\
\hline & OR $(95 \% \mathrm{CI})^{\mathrm{b}}$ & $\mathrm{p}$ value & OR $(95 \% \mathrm{CI})^{\mathrm{b}}$ & $\mathrm{p}$ value & OR $(95 \% \mathrm{CI})^{\mathrm{b}}$ & $\mathrm{p}$ value \\
\hline Change in $6 \mathrm{MWT}$ & $1.12(0.66-1.94)$ & 0.66 & $1.38(0.96-1.96)$ & 0.08 & $1.35(1.04-1.75)$ & 0.02 \\
\hline Baseline 6MWT & $2.68(1.37-5.23)$ & $<0.01$ & $2.86(1.80-4.54)$ & $<0.01$ & $2.92(2.08-4.11)$ & $<0.01$ \\
\hline Change in COPD severity score & $2.06(1.16-3.67)$ & 0.01 & $2.25(1.51-3.36)$ & $<0.01$ & $1.92(1.45-2.55)$ & $<0.01$ \\
\hline Baseline COPD severity score & $2.02(1.17-3.50)$ & 0.01 & $1.98(1.36-2.88)$ & $<0.01$ & $2.44(1.84-3.23)$ & $<0.01$ \\
\hline Change in percent predicted $\mathrm{FEV}_{1}$ & $1.31(0.69-2.50)$ & 0.41 & $1.61(1.05-2.47)$ & 0.03 & $1.47(1.10-1.97)$ & $<0.01$ \\
\hline Baseline percent predicted $\mathrm{FEV}_{1}$ & $2.18(1.06-4.44)$ & 0.03 & $1.70(1.07-2.68)$ & 0.02 & $1.66(1.21-2.27)$ & $<0.01$ \\
\hline
\end{tabular}

${ }^{a}$ Newly unable to perform defined as a new rating of 'unable' in any activity domain from $\mathrm{T} 0$ to $\mathrm{T} 1$.

${ }^{\mathrm{b}}$ ORs expressed per standardized $\mathrm{Z}$ unit (1 SD range) decrements in $6 \mathrm{MWT}$ and percent predicted $\mathrm{FEV}_{1}$ or increase in COPD severity score, all of which were tested in separate multivariable logistic regression models that included the baseline value of the predictor as well as its change over time. All models also include gender, age, BMI, change in BMI, race, smoking status and second-hand smoke exposure.

VLA $=$ Valued Life Activities.

\section{Discussion}

We found that, in working-aged adults with COPD, greater impairments and poorer pulmonary and extrapulmonary functioning predicted the development of incident disability. Although spirometic lung function was predictive of disability, so too was $6 \mathrm{MWT}$ and an integra- tive COPD severity score that does not require either lung function or exercise testing. Moreover, measures of extrapulmonary impairment (quadriceps strength) and function (SPPB) also predicted incident disability. Finally, within a hierarchy of activities, those considered discretionary were the most vulnerable to the development of disability and manifested the most consistent relation- 
ship with both baseline and change in the independent predictors studied. Notably, discretionary activities are those least commonly assessed in traditional measures of ADL functioning.

These findings offer important insights into the COPD disablement process. Not only is COPD a respiratory disease, it is also a systemic process with effects on body systems distant from the lungs. Our study provides prospective epidemiological evidence that these effects on extrapulmonary body systems predict the development of disability in patients with COPD. It is likely, therefore, that interventions aimed exclusively at improving pulmonary function are unlikely to fully mitigate COPDrelated disablement.

We also identified a gradient in the development of disability that also has relevance for preventive strategies. Discretionary activities appear to represent a particularly vulnerable and 'sensitive' measure of the impact of COPD on disability. Over a follow-up period of only 2.5 years, $10 \%$ of subjects developed disability in discretionary activities. Moreover, this risk of disablement was 5-fold higher than the risk observed in the obligatory category, a category that subsumes (I)ADLs. In addition, in COPD, the disability in discretionary activities is strongly associated with the development of depression [35]. Thus, narrowly defining disability as (I)ADLs substantially underestimates the burden of COPD on daily life [21]. Thus, interventions aimed at COPD disability prevention should measure disability broadly across a spectrum of activities considered important to patients.

Our study builds upon previous work to advance the understanding of the disablement process in COPD; indeed, it reflects the growing appreciation of COPD as a systemic disease process. We systematically quantified the impact on COPD-related disability of both pulmonary and extra-pulmonary body systems at baseline and over time. Most longitudinal studies of disability in COPD have focused on advanced disease [39-41] (for which interventions to prevent disablement may be less effective), the elderly [42], hospitalized subjects [39, 43] or on (I)ADLs [41, 42]. By longitudinally studying a working-aged population with a wide range of disease severity, our findings are particularly relevant to ambulatory COPD populations at early risk for disability. Moreover, most previous studies of COPD have defined disability based on (I)ADLs. Although widely used to study disability in debilitated populations, (I)ADLs have limited utility in ambulatory populations because of a 'floor' effect in which most subjects score rather well and do not appear to change over time. By defining disability across a broad range of activities, we identified a heretofore unobserved gradient in the prospective development of disability. Finally, we demonstrated that the COPD severity score, a method of disease severity assessment that does not require measuring pulmonary function, is as strong a predictor of disability as laboratory-based measures of pulmonary and extra-pulmonary functioning. This may be useful for epidemiological studies aiming to risk-adjust for disease severity or to identify subjects at higher risk of developing disability.

Our study also faces limitations. Of the 1,051 subjects reinterviewed, $69 \%$ completed follow-up clinic visits. Of these, $10 \%$ were excluded from this analysis due to inadequate/missing spirometry data. It is possible that death, a refusal to continue to participate or loss to follow-up may have introduced selection bias. The 310 subjects who did decline a follow-up visit were more likely to be current smokers and had worse exercise capacity. Thus, it is likely that any selection bias introduced would have resulted in an underestimation of disability risk. Our method of ascertaining a COPD diagnosis may also have resulted in misclassification, although our algorithm required utilization of COPD services, concomitant treatment with COPD medications and a physician diagnosis of COPD and was validated against a sample chart review [22]. In addition, the primary aim of this longitudinal study was to identify predictors of COPD-related disability; accordingly, subject recruitment was limited to working-aged adults. Thus, while our findings are particularly applicable this population, our results may not be generalizable to older patients. Finally, there was, on average, little change in lung function over the observation period, even though within the group there were some subjects who declined rapidly; this appears to be consistent, however, with the heterogeneous natural history of COPD [44]. Despite these potential limitations, we identified factors that predict the development of disability over a relatively short period of time in an ambulatory COPD population and across a broad range of activities.

In summary, decrements in lung function as well as in body systems far away from the lungs are important predictors of the development and progression of COPD-related disablement. We also delineated a hierarchy of disablement in which discretionary activities are most vulnerable. Our findings suggest that interventions designed to prevent disability in COPD should comprehensively target both pulmonary and extra-pulmonary factors and should be initiated at the time disability appears in discretionary activities. 


\section{Acknowledgements}

Work was conducted at Kaiser Permanente Division of Research and UC San Francisco. It was funded by the National Heart, Lung and Blood Institute/National Institutes of Health R01HL077618, K24 HL 097245 and F32 HL107003-01, the Flight
Attendant Medical Research Institute (FAMRI Bland Lane Center of Excellence on Second-hand Smoke) and the University of California Tobacco-Related Diseases Research Program (17RT0101). A portion was also supported by the National Center for Research Resources at the National Institutes of Health (UCSFCTSI UL1 RR024131).

\section{References}

1 Iglehart JK: Prioritizing comparative-effectiveness research - IOM recommendations. N Engl J Med 2009;361:325-328.

- Verbrugge LM, Patrick DL: Seven chronic conditions: their impact on US adults' activity levels and use of medical services. Am J Public Health 1995;85:173-182.

-3 Murray CJ, Lopez AD: Alternative projections of mortality and disability by cause 1990-2020: Global Burden of Disease Study. Lancet 1997;349:1498-1504.

-4 Eisner MD, Yelin EH, Trupin L, Blanc PD: The influence of chronic respiratory conditions on health status and work disability. Am J Public Health 2002;92:1506-1513.

5 Eisner MD, Blanc PD, Yelin EH, et al: COPD as a systemic disease: impact on physical functional limitations. Am J Med 2008;121: 789-796.

6 Gan WQ, Man SF, Senthilselvan A, Sin DD: Association between chronic obstructive pulmonary disease and systemic inflammation: a systematic review and a meta-analysis. Thorax 2004;59:574-580.

7 Tkacova R, Ukropec J, Skyba P, et al: Increased adipose tissue expression of proinflammatory CD40, MKK4 and JNK in patients with very severe chronic obstructive pulmonary disease. Respiration 2011;81: 386-393.

$\checkmark 8$ American Thoracic Society and European Respiratory Society Statement: Skeletal muscle dysfunction in chronic obstructive pulmonary disease. Am J Respir Crit Care Med 1999;159:S1-S40.

-9 Singer J, Yelin EH, Katz PP, et al: Respiratory and skeletal muscle strength in chronic obstructive pulmonary disease: impact on exercise capacity and lower extremity function. J Cardiopulm Rehabil Prev 2011;31:111-119.

10 Speizer FE, Fay ME, Dockery DW, Ferris BG Jr: Chronic obstructive pulmonary disease mortality in six US cities. Am Rev Respir Dis 1989;140:S49-S55.

-11 Antoniu SA: Predictors of depression in chronic obstructive pulmonary disease patients. Expert Rev Respir Med 2011;5:333335.

12 Ionescu AA, Schoon E: Osteoporosis in chronic obstructive pulmonary disease. Eur Respir J 2003;46(suppl):64s-75s.
3 Boutou AK, Stanopoulos I, Pitsiou GG, et al: Anemia of chronic disease in chronic obstructive pulmonary disease: a case-control study of cardiopulmonary exercise responses. Respiration 2011;82:237-245.

14 Bestall JC, Paul EA, Garrod R, Garnham R, Jones PW, Wedzicha JA: Usefulness of the Medical Research Council (MRC) dyspnoea scale as a measure of disability in patients with chronic obstructive pulmonary disease. Thorax 1999;54:581-586.

15 Rodriguez Gonzalez-Moro JM, de Lucas Ramos P, Izquierdo Alonso JL, et al: Impact of COPD severity on physical disability and daily living activities: EDIP-EPOC I and EDIP-EPOC II studies. Int J Clin Pract 2009; 63:742-750.

16 Pitta F, Troosters T, Spruit MA, Probst VS, Decramer M, Gosselink R: Characteristics of physical activities in daily life in chronic obstructive pulmonary disease. Am J Respir Crit Care Med 2005;171:972-977.

17 Watz H, Waschki B, Meyer T, Magnussen H: Physical activity in patients with COPD. Eur Respir J 2009;33:262-272.

18 Watz H, Waschki B, Boehme C, Claussen M, Meyer T, Magnussen H: Extrapulmonary effects of chronic obstructive pulmonary disease on physical activity: a cross-sectional study. Am J Respir Crit Care Med 2008;177: 743-751.

19 Nagi SZ: An epidemiology of disability among adults in the United States. Milbank Mem Fund Q Health Soc 1976;54:439-467.

20 Verbrugge LM, Jette AM: The disablement process. Soc Sci Med 1994;38:1-14.

21 Katz PP, Gregorich S, Eisner M, et al: Disability in valued life activities among individuals with COPD and other respiratory conditions. J Cardiopulm Rehabil Prev 2011;30: 126-136.

22 Sidney S, Sorel M, Quesenberry CP Jr, DeLuise C, Lanes S, Eisner MD: COPD and incident cardiovascular disease hospitalizations and mortality: Kaiser Permanente Medical Care Program. Chest 2005;128:2068-2075.

23 American Thoracic Society and European Respiratory Society Statement: Respiratory muscle testing. Am J Respir Crit Care Med 2002;166:518-624.

24 Hankinson JL, Odencrantz JR, Fedan KB: Spirometric reference values from a sample of the general US population. Am J Respir Crit Care Med 1999;159:179-187.
25 Eisner MD, Trupin L, Katz PP, et al: Development and validation of a survey-based COPD severity score. Chest 2005;127:1890-1897.

-26 Eisner MD, Omachi TA, Katz PP, Yelin EH, Iribarren C, Blanc PD: Measurement of COPD severity using a survey-based score: validation in a clinically and physiologically characterized cohort. Chest 2010;137:846851.

27 Omachi TA, Yelin EH, Katz PP, Blanc PD, Eisner MD: The COPD severity score: a dynamic prediction tool for health-care utilization. COPD 2008;5:339-346.

28 Guyatt GH, Sullivan MJ, Thompson PJ, et al: The 6-minute walk: a new measure of exercise capacity in patients with chronic heart failure. Can Med Assoc J 1985;132:919-923.

29 Coronell C, Orozco-Levi M, Mendez R, Ramirez-Sarmiento A, Galdiz JB, Gea J: Relevance of assessing quadriceps endurance in patients with COPD. Eur Respir J 2004;24: 129-136.

30 Kendall F, McReary E, Provance P: Muscles: Testing and Function. 4. Baltimore, Williams \& Wilkins, 1993.

31 Gosselink R, Troosters T, Decramer M: Peripheral muscle weakness contributes to exercise limitation in COPD. Am J Respir Crit Care Med 1996;153:976-980.

- 32 Guralnik JM, Ferrucci L, Simonsick EM, Salive ME, Wallace RB: Lower-extremity function in persons over the age of 70 years as a predictor of subsequent disability. $\mathrm{N}$ Engl J Med 1995;332:556-561.

33 Guralnik JM, Simonsick EM, Ferrucci L, et al: A short physical performance battery assessing lower extremity function: association with self-reported disability and prediction of mortality and nursing home admission. J Gerontol 1994;49:M85-M94.

-34 Katz PP, Yelin EH: Life activities of persons with rheumatoid arthritis with and without depressive symptoms. Arthritis Care Res 1994;7:69-77.

35 Katz PP, Gregorich S, Eisner M, et al: Disability in valued life activities among individuals with COPD and other respiratory conditions. J Cardiopulm Rehabil Prev 2010;30: 126-136.

-36 Centers for Disease Control and Prevention: Cigarette smoking among adults - United States, 1997. MMWR Morb Mortal Wkly Rep 1999;48:993-996. 
37 Eisner MD, Katz PP, Yelin EH, Hammond SK, Blanc PD: Measurement of environmental tobacco smoke exposure among adults with asthma. Environ Health Perspect 2001; 109:809-814.

38 Bailar JC, Ederer F: 202. Note: significance factors for the ratio of a Poisson variable to its expectation. Biometrics 1964;20:639643.

39 Connors AF Jr, Dawson NV, Thomas C, et al: Outcomes following acute exacerbation of severe chronic obstructive lung disease. The SUPPORT investigators (Study to Understand Prognoses and Preferences for Outcomes and Risks of Treatments). Am J Respir Crit Care Med 1996;154:959-967.
40 Graydon JE, Ross E, Webster PM, Goldstein RS, Avendano M: Predictors of functioning of patients with chronic obstructive pulmonary disease. Heart Lung 1995;24:369-375.

41 Okubadejo AA, O’Shea L, Jones PW, Wedzicha JA: Home assessment of activities of daily living in patients with severe chronic obstructive pulmonary disease on long-term oxygen therapy. Eur Respir J 1997;10:15721575 .
2 Isoaho R, Puolijoki H, Huhti E, Laippala P, Kivela SL: Chronic obstructive pulmonary disease and self-maintaining functions in the elderly - a population-based study. Scand J Prim Health Care 1995;13:122-127.

43 Peach H, Pathy MS: Follow-up study of disability among elderly patients discharged from hospital with exacerbations of chronic bronchitis. Thorax 1981;36:585-589.

44 Casanova C, de Torres JP, Aguirre-Jaime A, et al: The progression of chronic obstructive pulmonary disease is heterogeneous: the experience of the BODE cohort. Am J Respir Crit Care Med 2011;184:1015-1021. 